the purlins, the latter 6 -inch I-beams about 6 feet 10 inches apart. The dove-tailed corrugations gave suffcient bonding surface, and the sheets were stron enough to sustain the weight of the concrete without forms. For the small ornamental arches, light furre steel angles covered with metal lath were used. Within the columns are 4-inch pipes to carry off the roo water.

Generally speaking, the stadium is supported by piers, five in a row, in lines about 15 feet apart on the sides and at distances of $40 \mathrm{deg} .30 \mathrm{~min}$. on the curvin ends. These piers go down to the original soil, which necessitated in some cases, where a considerable fill had been made, a 25-foot or more well. The ground varied-hardpan, sand, loam, and gravel.

The contractors say:

"It was assumed that 600 pounds per square inch would constitute a safe load for columns reinforced with vertical rods and hooping, and 400 pounds per square inch for columns reinforced, but not hooped. These assumptions were, however, without importance, as other conditions governed the size of the columns. In general they were made of uniform size, of rectangular shape, 12 inches by 30 inches, reinforced with four Kahn bars, weighing 2.7 pounds per foot. The re tangular shape was adopted in order to resist the effect of any sliding tendency that the bank might have. Where it was necessary to use columns of great length, they were made square, with a side not less than $1 / 15$ of the length of the column. These columns were reinforced with four round rods of $7 / 8$ inch diameter and wrapped with Clinton wire cloth 3 inches by 8 inches mesh, 8-10 wire. In general all parts of the
One of the most serious problems in concrete conOruction, handled most successfully at Syracuse, is to prevent cracking because of contraction due to temperature or local changes. To obviate this some designers leave straight contraction joints at regular intervals. It was decided at Syracuse to use more reinforcing steel as being more sightly and cheaper in the end. It was estimated that steel to concrete in the proportion of $1 / 3$ of 1 per cent would be sufficient to prevent cracking and this percentage was observed throughout. As further preventives all horizontal Kahn bars overlap 2 feet and Clinton wire cloth covers all exposed places.

Another problem was to secure a pleasant surface appearance, and here special pains were taken. The rough surface left by forms was out of question, however carefully worked. And plastering set concrete work usually fails because of the difficulty of securing a good bond. This was, however, accomplished at Syracuse by special and ingenious means. Wire nails were driven into the forms at frequent intervals. On removing the forms their pointed ends projected some 2 inches from the rough concrete. A small iron nut was slipped over each nail, the concrete was covere with wire lath, and the nails bent over with a hammer. The nuts thus kept the wire lath about $1 / 4$ inch from the old concrete. The plaster finish, averaging an inch thick, was put on in two coats, a scratch coat and a finishing coat of 1 part cement to $13 / 4$ parts white Long Island beach sand. This was troweled smooth. This part of the work was protected from the sun by temporary wooden sheds; and during its hardening the finishing coat was covered with burlap

\section{FISH DOCTORING.}

BY PETER COLRMAN.

Most people know that every large zoological collection has its hospital department for the treatment of sick beasts and birds, but few are aware that similar institution is attached to a big aquarium. Such, however, is the case. Like all other captive creatures, fishes kept in tanks are liable to numberless hurts and ailments; and it has been found that a little timely treatment, either hygienic or surgical, will often suffice to revivify a sickly specimen. In the case of a rare fish, death would often prove a serious loss to the scientific world. So it has come about that the fish doctor is an important functionary at a big aquarium. $\mathrm{He}$ has his staff of assistants, his isolation tanks, his operating tanks, his convalescent tanks, with all manner of clever contrivances for the successful exercise of his profession.

Fish doctoring was first seriously taken in hand at the largest, the finest equipped, and the most up-to-date aquarium in the world, namely, that which overlooks the bay of New York, almost opposite the island crowned with the giant statue of Liberty. More recently, however, similar institutions in different parts of the world have followed the example set by America, for it is now generally realized that if fish are to be healthy, they must have individual care bestowed upon them over and above that given to the food with which they are supplied, and the temperature and purity of the water in which they swim.

Since the time when fish hospitals came into being, many interesting facts relating to fish hygiene have been established. For example, it is now known that

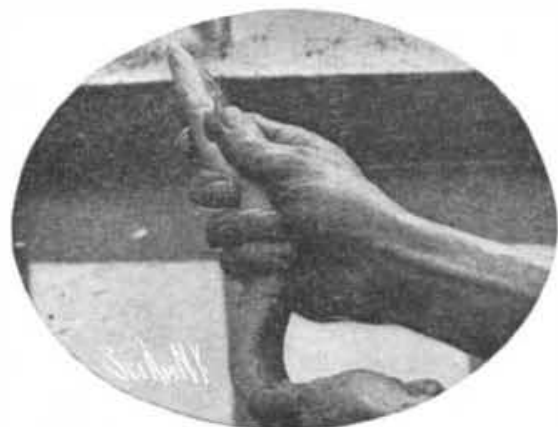

An Eel is a Dificult Fish to Handle.

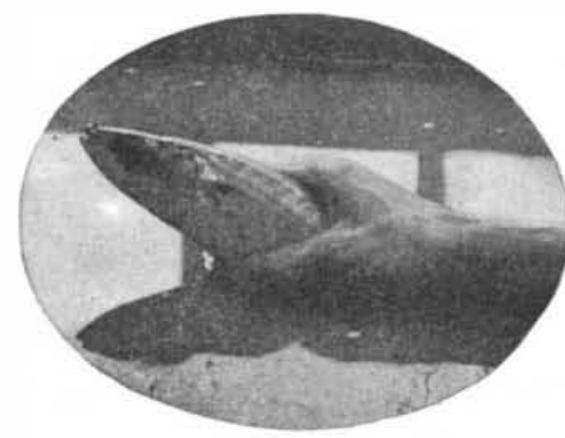

Capturing a Fish in the Operating Tank.

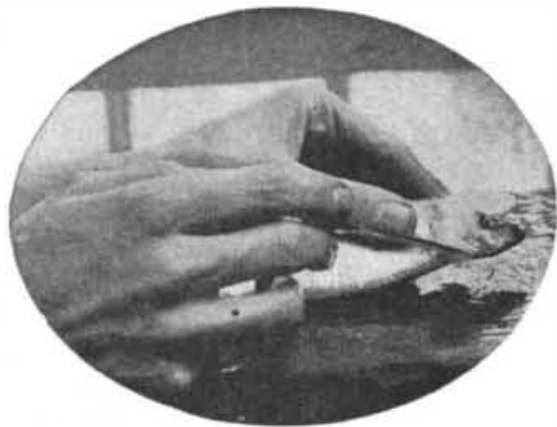

Removing Fungoid Growth trom a Carp's Gills.

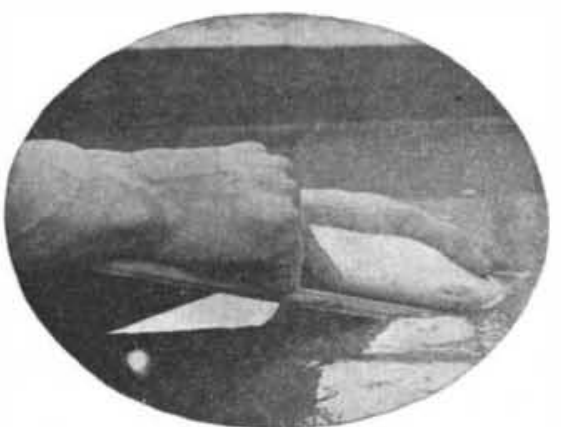

Massaging a Fish to Reduce Swelling of Air Bladder.

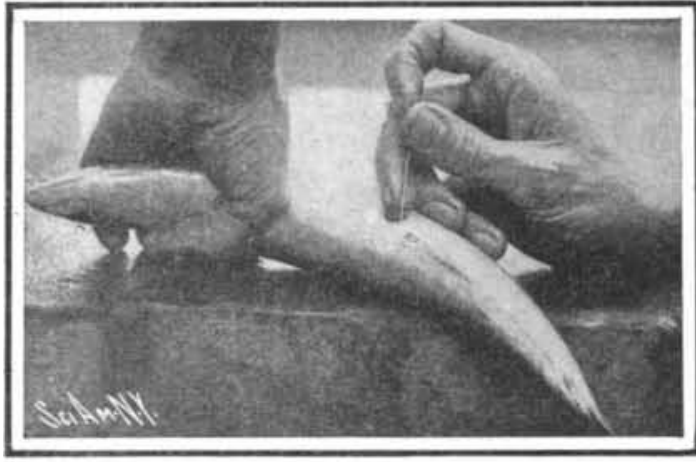

Lancing to Reduce Air Bladder Pressure.

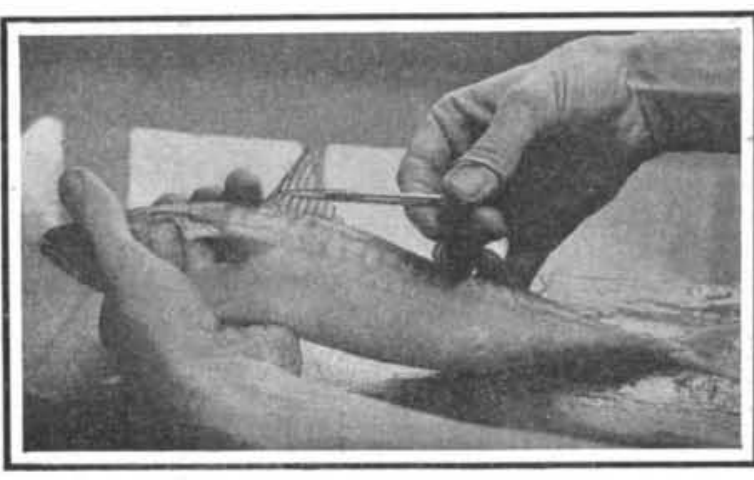

Operating on a Diseased Fin.

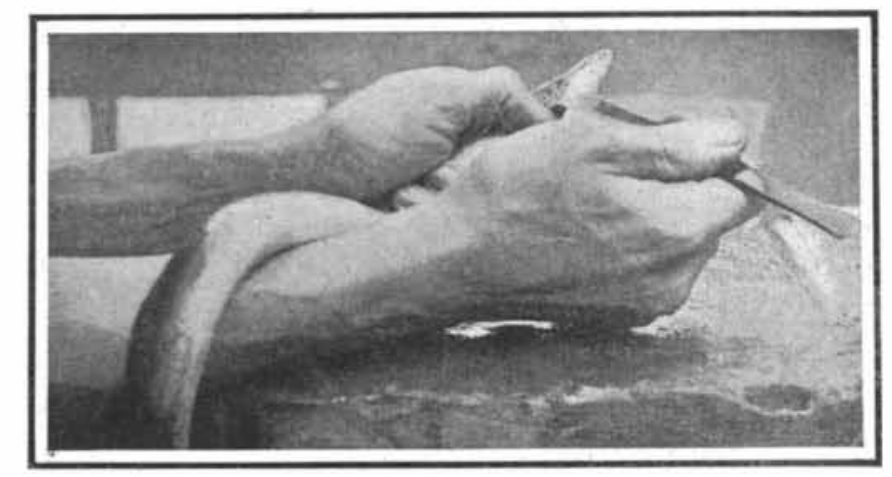

Removing Growth from the Gills of an Eel.
FISH DOCTORING.

structure were figured for a live load of 100 pounds per square foot, except the promenade, which was designed for 120 pounds, and the roofs over the grand stand and main entrance, which were figured for a live load of 40 pounds per square foot.

In calculating bending stresses, the straight line formula was used throughout, and the tensile strength of the concrete was neglected. It is of course realized that this formula is not scientifically correct, but in this respect it probably does not differ from any of the other formulæ at present in use.

The safe compression stress for concrete was in this case assumed to be 600 pounds per square inch and the safe tensile stress for steel 16,000 pounds per square inch. The girders, steps, and the slab of the promenade were figured continuous and the maximum bending moment was assumed to be $W L \div 12$ where $W \cdot$ represents the total dead and live load and $L$ the $W \cdot$ represents the total dead and live load and $L$ the
distance between supports. The negative bending distance between supports. The negative bending
moment over the supports was assumed to be $W L \div$ 18 and steel was provided according to this assumption.

The main reinforcement for girders, steps and promenade consists of Kahn bars, with stirrups varying in length from 6 inches to 30 inches. In addition to the Kahn steel, Clinton wire cloth has been placed 11/ inches below the surface of all concrete exposed to view. This was done solely in -order to prevent cracking, as much as possible, and the Clinton wire cloth was not taken into consideration when figuring the bearing capacity of the concrete. The slzes used were 4 inches by 6 inches mesh 10-10 wire, 30 inches yide, for the steps and 3 inches by 8 inches mesh, 8-10 wire, 72 inches wide, for other places. and sand kept wet. The care taken justifies itself in a smoothness and beauty of finish remarkably effec-

The work was begun by the university directly and during some two years considerable excavating was done. The contractors, on taking over the work, installed an industrial railroád and completed the excavation and construction in about a year. The plai concrete for the work was cement, sand, and broken stone mixed in the proportions $1,3,5$; the reinforced concrete in the proportions $1,2,4$. The stone used was mostly limestone; the sand from a bed near the west end of the field, discovered in excavating. All mixing was mechanical, the plant consisting of fiv Ransome mixers with engines and boilers and a smal Smithe auxiliary.

On the east end the field connects by tunnel with a new gymnasium, 150 feet by 220 feet, now being erected. This :will also be perhaps the largest and finest in the world. A feature will be the pools; one, for swimming, of reinforced concrete lined with white tile, measures 32 feet by 90 feet.

The original idea of the stadium was Chancello James R. Day's. The funds were provided by Mr. John D. Archbold, and the cost is already understoo to have exceeded half a million dollars. The architects were Messrs Revels \& Hallenbeck, the heads of the Department of Architecture of the College of Fine Arts of the 'University,

The following facts may be of interest: Area covered, 61/3 acres; excavation, 250,000 cubic yards; reinforced concrete, 20,000 cubic yards; reinforcin steel used, 500 tons; Clinton wire cloth, 280,000 square feet; galvanized metal lath, 220,000 square feet. a diseased fresh-water fish commonly derives marked benefit from a sojourn in salt water, and vice versa. This "change of water" treatment is especially successful as a cure for fungoid growths, to which many fishes-especially the smaller kinds-are much subject. The water to which sickly fresh-water fish are transferred is composed partly of water taken direct from the ocean, partly of river water. The result, of course, is a highly brackish solution; and this is kept at a slightly higher temperature than the water from which the invalid was taken. In like manner, an occasional bath of fresh water of the right temperature has been found very beneficial to sea fishes.

We have said that it is not enough to feed the fish regularly and systematically, and to cleanse their tanks periodically. The keepers must also be constantly on the watch lest their charges develop disease, or become damaged by fighting, or by collision with the glass walls of their tanks a bruised specimen quickly develops the dreaded fungus disease, which not only disfigures and ultimately destroys the injured fish, but rapidly infests its companions in captivity. A plant parasite known as Saprolegnia is very destructive to fresh-water fishes; while other disfiguring growths are of constant occurrence, especially in the case of neglected tanks. As we have seen, a total change in the chemical character of the water is often very effective as a cure, while applications of formalin to the affected parts are said to be useful in mil cases. Fishes cannot, however, endure medicine, while the extreme delicacy of their skins renders even the handling of them exceedingly difficult.

At times, however, surgical operations become abso lutely necessary, as in the case of a very bad grow.th 
of fungus about the gills. The fish, which has been previously placed in the operating tank, is carefully lifted therefrom by means of a net: The surgeon then grasps the patient firmly, but as gently as possible, with the left hand, and with a scalpel held in his right removes the foreign substance. Abscesses are also lanced, but it is seldom that these operation prove successful, and they are only resorted to in extreme cases. The reader, after a moment of thought, will realize the unusual difficulties which beset fis surgery. A fish is a creature of the water. It is impossible for it to sustain life in the air for more than a limited period of time. Just as soon as it is re moved from its natural element, it begins slowly to die. Indeed, an operation on a fish is performed under much the same conditions as would obtain if a surgeon were to remove a human patient from his warm bed and hold him beneath cold water while he plied his lancet.

Nevertheless, fish surgery is by no means an un broken record of failures. On the contrary, an despite its attendant difficulties, some notable successe have been scored. Perhaps the most daring piece of work that has been performed at the New York aquarium was the removal of a fungoid growth from on of the fins of a five-foot shark, while the most difficult was the grafting of skin upon an eel. That the latte proved a slippery patient, the reader will readily conjecture. Indeed, the holding of piscine patients while they are being operated upon is a serious problem, which must. be solved by means of specially-made boxes, soft wrappings, and the like contrivances.

The most frequent successful operations are performed upon fishes whose air-bladders fail to effect their proper functions. The chief cause of such defects is the too rapid removal of a fish from the wate to the air, as when it is captured, or removed from one tank to another. It is brought quickly to the surface with its mouth open. Its air bladder is charge to a greater or less extent with water, which enables it to maintain its specific gravity in deep waters. But the suddenness with which the fish is jerked out of it natural element prevents it from correctly adjustin the quantities of air and water in the bladder, an congestion results. When returned to its tank, the wretched creature is unable to sink or is washed about by the movements of the water in helpless condition.

It has been found that fishes injured in this way may often be cured by a little gentle massage. Th operator grasps the fish firmly with the left hand by the tail, draws it carefully out of the water up an inclined board reaching into the tank, but allowing the head and shoulders to remain submerged. Massage is then commenced toward the gills; and generally, after a few minutes' action of the hand, the air is forced out of the bladder.

Massage does not always prove successful in relieving the trouble, however, and more drastic measures have to be resorted to. In the case of a deep-sea bass, which had lost complete control of its air-bladder, and lay wallowing on the surface, quite unable to sink or swim, it was recognized that a remedy must imm diately be found if the fish were to be saved. Th bass was taken from the water, and a surgeon's needle inserted just behind the pectoral fin into the air bladder. The air was thus liberated, and the patient was a. hospital tank healed the slight puncture, and effected his complete cure.

This fish seemed fully to appreciate the servic which had been rendered him. Indeed, those who have charge of sick fishes aver that their patients appear conscious that they are being treated for their good. Fishes which in the normal condition of goo health are fierce and wayward become docile when they have been for a short time in hospital. More over, while care is necessary in the mixing of fishe of different species in ordinary circumstances, thi does not apply to the hospital tanks. Patients which would be ready to fight to the death when in health, become perfectly companionable when laboring under the common misery of disease.

In contrast to this, it is interesting to learn that convaiescert fish must not be returned at once to his old tank. Either he, with his renewed vitality, will evince a pugnacious desire toward his old companions, or they on their part may set upon him and slay hin. In fine, it is found necessary to exercise the utmost caution when introducing a stranger fish to a tank At the New York Aquarium an angel fish (whose name, by the way, did not fit with his nature) had to be sentenced to solitary confinement because of his $\mathrm{v}$ cious propensities. He had killed two of his com rades, and exhibited every intention of trying his strength with others, when he was removed from the tank.

In conclusion, it may be said that the keepers at big aquarium become wonderfully adept at diagnosin the condition of their charges. By merely lookin intently through the glass walls of the tanks, they ca tell whether the inmates are well or whether the show symptoms of disease. Just as the reader is able
to say that his friend is ill or well by looking in his face, watching his behavior, and so on, the fish keeper is warned by the appearances of his charges as to their physical condition. A black bass dying from asphyxiation, for instance, becomes pale and wan in aspect though five minutes after death it regains its natura color. Other sickly fish exhibit changes of color, or they swim and feed in an abnormal manner; and from these signs the attendant argues that he has patient for the hospital. This watchfulness has been the means of saving many valuable fish lives, both in the big New York Aquarium and in similar institutions in Europe.

\section{How to Construct and Operate a \\ One-Man Airship.}

After thirty years of knowledge and experience in aeronautics, I feel that I can give a few data that will enable the young inexperienced aeronaut to arrive
at better results than he seems able ordinarily to obtain.

In constructing a small dirigible balloon, the first and most essential thing is to make a perfect envelope which can only be had after careful labor. Cotton may be used, but silk makes by far the better gas bag. It is three or four times as strong as cotton, and will last ndefinitely with proper care.

The silk must first be cut in lengths of from twenty to thirty yards, according to the size it is desired to make the envelope. Next the silk must be given a thorough bath, in either linseed or spar" oil, and hung up by one end to dry, so that the oil will run to the bottom and dry evenly. The drying process depends on the climatic conditions, and I have had it take from one week to five months for my silk to dry. The silk must be thoroughly dry before cutting and sewing.

After the silk has been prepared, the next step is to make a pattern for a single gore of the gas bag, or for a half or at least a quarter of such a gore.

In drafting and cutting the pattern, great care should be taken to see that it is absolutely correct in outline, as if there is the slightest irregularity the silk will draw and tear. The edge of each gore should be cut on a curve which is laid out in the following manner upon a paper pattern: A strip of paper of the same dimensions as a length of the silk is fastened horizontally on a wall. A string is then suspended from two tacks placed at each end of the strip, midway of its width, and allowed to sag until it touches the bottom of the strip. The line thus formed will be the desired curve. The only point to remember is that the gores must be of the proper width to give the desired circumference at the center and that there must be enough margin left to allow for overlapping the seams. Once the pattern is obtained, the cutting is easily accomplished.

I have found the most economical and reliable one man airship to be one made to the dimensions of my "California Arrow," the length of which is three times the diameter, while three and a half times would still be a good proportion. The seams should all be double stitched. The strips are first sewed together with a plain seam about $1 / 2$ inch from the edge. The raw edges are then turned under about $1 / 8$ inch, and sewed down by a second line of stitching $1 / 4$ inch from the first line, thus forming a lap seam. The sewing should be done with good silk.

About two feet from the bottom center of the en velope, make a large neck, or manhole, so the bag can be turned wrong side out and varnished. Directly above this manhole, in the top, a 14-inch valve may be fitted. Although the valve is merely a matter of personal desire, I do not advise building an airship without one. Should the valve be inserted, there must be a cord coming down to the manhole, so that it can be usedif needed. About four feet back of the manhole, put in a small neck about six inches in diameter, for filling the bag with gas.

Now the bag being sewed and ready for the coating varnish, take a six-inch brush and after the envelope shape, commence at one end and paint one or two gores the entire length of the bag. When these have been very carefully done, take the next two gores, and so on until the entire envelope has had the secon coating. After this is absolutely dry, turn inside out and do the same thing over. These coats of varnish must be put on until the envelope is air tight, and there is .., leakage. Be careful to watch the envelope when filled with air, as the change in temperature will cause the air to expand and is liable to burst the bag, but after watching it a day or two, the hours for expansion and contraction will soon be learned.

This envelope should be entirely incased in a linen square mesh netting, and never a diamond shape, as there will be no end of give with the diamond mesh, and it will be difficult to control the airship when in the air. The squares should be about six inches, and for a ship the size of the "California Arrow" there should be-about sixty -suspension cords of alternately

6 and 8 feet in length, placed some two and a half feet apart and extending the entire length of the frame. There will be two cords on each point of the finished netting, one for the top and one for the bottom of the rame.

The frame, which is about 45 feet long, should be built of $1 \frac{1}{2}$-inch Oregon spruce. It is in the form of an equilateral triangle, and it should be braced ever three feet with a $11 / 2 \times 1 / 2$-inch strip, the panels thus ormed being braced diagonally with piano wire.

The frame should hang about six feet from the bottom of the envelope and should be perfectly adjusted, so that an equal strain will come on each suspension cord.

The propeller should be a two-bladed one, ten feet in diameter, with the pitch about equal to the diameter, and a blade width of 18 inches at the tip. It should be geared to make about 175 revolutions per minute, which is a peripheral speed of the blades of 5,498 feet per minute. The longer the blade and the slower the speed, the more efficient is the propeller within certai limits. The propeller shaft should be made of 16 gage, $11 / 4$-inch seamless steel tubing. The

A 7-horface of 36 square feet. A 7-horse-power air-cooled motor of about 50 pounds
weight is sufficient power for this size airship, as the full power of a larger engine cannot be used, and for the novice a 7-horse-power engine is quite sufficient. The motor should be placed about one-third of the distance from the front of the framework and suitably geared to the propeller. A clutch can be fitted if desired, but this is not absolutely necessary. The engine should be carefully watched at all times, as the success of an airship depends upon the motor. The engin should be rigidly inspected each time before going in the air, and special attention should be given to its lubrication, which must be very thorough.

During 1907. I made ninety-two starts, returning to the exact starting point ninety-one times. On the one trip from which I did not return under my own power, the wind came up stronger than the thrust of the propeller, and therefore I was helpless, but my valve gave me the means of a safe descent. Never go into th air when the wind has more power than you have, and you will have little or no trouble. An eight-milean-hour wind is a safe limit; although an experienced operator can operate in a wind of from twelve to fifteen miles an hour. Accidents are not necessary if the operator is sure that everything is in working order before he makes an ascension, for when you are onc in the air, and things go wrong, it is then too late to remedy them and you will have to take the consequences.

Following are the dimensions of the "California Arrow" which may be used as a pattern: Length, 52 feet; diameter, 17 feet, with a capacity of 9,000 cubic feet. Made of the best Japanese silk, coated with linseed oil varnish. Irish linen netting. Frame, equilateral triangle, 45 feet long by $3 \times 3$ feet wide, and equipped with a Curtiss 7 horse-power motor of 50 pounds weight. Two-blade screw propeller, 10 feet in diameter and 10-foot pitch, with 18-inch width of blade at tip; peripheral speed, about 5,000 feet per minute. Shaft connected with a countershaft, but no clutch . i used. The speed is controlled by a rod eight feet long extending forward from operator to motor and connected to the throttle. The rudder contains 36 square feet of surface. The tiller rope is continuous and passes around a pulley in front of the operator. The rudder can thus easily be controlled by one hand. One thousand cubic feet of gas will lift 65 pounds. The formula for making the gas is 1,000 pounds of sulphuric acid, 1,000 pounds of iron, 5,000 pounds of water, which should generate 3,500 cubic feet of gas.

After the frame and engine and all connections are finished, the airship is ready for its first flight. The airship, of course, is supposedly under cover and protected from bad weather while waiting for the start. The very last thing to do before leaving the aerodrome is to ballast the airship. Mount the frame and arrang things so that the center of balance is about 5 feet back of the motor. Add or take from the ballast until there is about three pounds of ascensive power, and then you are ready for a flight. This should be done about fiftzen or twenty minutes before the time of ascension, so that there will be no delay whatever when the minute arrives. After stepping from the frame and having the ship anchored, walk around and look carefully over everything. The manhole and inflating neck should be made into a safety valve, by taking up several inches and twisting an elastic band 
You should have a drag rope of 100 feet attached to the frame about onethird from the back end. This should be carefully laid on the ground free from everything, so that when you rise it will not become entangled. You take your seat slightly back of the center of balance, with the engine running, and when you give the signal, the saw horses are knoclied out from under the frame, and you ascend at an angle of about 10 degrees by stepping back a foot or tw upon the frame which you are straddling. You now must use your own judgment about your flight, as to how long it will be and where you will try to go, but be careful not to turn your rudder too quickly. This should be operated by two tille ropes, one in each hand. Move slightly forward for descent, and backward for ascent. The spark and throttle contro rods run back along the frame, and can be operated at all points where you stand. In coming down stop the motor about 25 or 30 feet from the ground, and have some one to catch the frame and save the propeller from striking the ground. With proper judgment the airship should come back to the exact starting point even as close as one or two feet. Afte the flight is ended, take the airship back to the aerodrome, guy it down carefully, shut off the gasoline disconnect the spark and watch the gas bag for expansion. With proper care the airship should sta in that condition indefinitely, and be ready for another flight when you so desire. (Continue from page 147.)

Five lessons will be supplied at one time, and the correct answers to the first set of questions will be sent when the second set is forwarded. The course will extend over a period of three months, and supplementary lessons on dirigible balloons and aeroplanes will be forwarded after being prepared by the French experts. Students who take this course will have the free use of a very complete library con. taining books and the leading magazines on the subject, as well as of a large number of stereoscopic photographs showing balloons, aeroplanes, etc., in flight. At Mr. Triaca's office, No. 108 West 49th Street, New York city, may also be seen models of balloons, aeroplanes, propellers, and motors, as well as samples of all kinds of accessories used by aeronauts. Among the privileges granted to students are that of consultation with the technical staff in Paris, and the benefit of the advice and assistance of its members; a balloon ascension either here or in Europe, which will be allowed to one student out of every twenty, the student to be selected by drawing lots; arrangement for special ascensions for members at a re duced cost whenever desired; and a 10 per cent discount upon subscrintions to aeronautical papers as well as on aeronauical instruments. At the conclusion of the course, each student will receive a suitable certificate.

IMPROVEMENTS IN TIMERS.

Pictured in the diagram directly opposite is a timer of the usual roller type, except that it is equipped with a novel self-cleaning device and also with a positive ground contact. The cleaning device consists of a brass gauze brush in closed in a fiber cap or retainer, and equipped with a spring which presse the gauze brush lightly against the track or surface on which the roller revolves. The gauze brush wipes or scrapes away any dirt, worn particles, or metal might accumulate on the contact surface and also the deposit that is formed by the arc of breaking contact as the rolle leaves a contact segment. On account of this surface being clean at all times, it is possible to use much shorter segments and a much larger roller. The slippage or drag usually found in small rollers is done away with, the roller making, but three and one-half revolutions to a complete turn, whereas from eight to eleve usually constitute a turn.

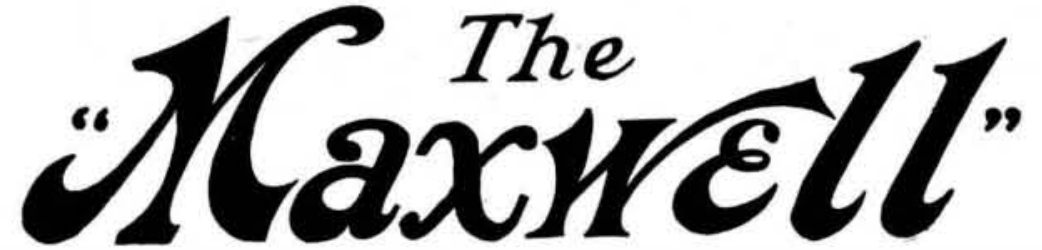

Details of Maxwell design, such as the three-point suspension, the thermo-syphon cooling system, unit construction, and others, which have proved their value with scientific exactness, are imitated to-day, but not combined in one other single car-except the Maxwell.

Universal approval has made the Maxwell

\section{The Most Popular American Automobile}

The 14 H. P. 2-cylinder Runabout, at $\$ 825$; the $20 \mathrm{H}$. P. 2-cylinder Touring Car, at $\$ 1,450$; the $24 \mathrm{H}$. P. 4-cylinder Touring Car, at $\$ 1,750$; the $24 \mathrm{H}$. P. 4-cylinder Roadster, at $\$ 1,750$ hold undisputed sway as the

\section{Aristocrats of Moderate=Priced Cars}

Like the jungle hunting sportsman who would not think of providing himself with a weapon other than of known reliability, the astute automobile buyer first of all investigates and then buys a car whose merit is proved.

When we can point to the fact that there are to-day more than 10,000 Maxwell automobiles in satisfactory daily use, it sounds like a good argument; doesn't it? Just the kind of argument that would cause you to take a good look at

\section{Maxirell}

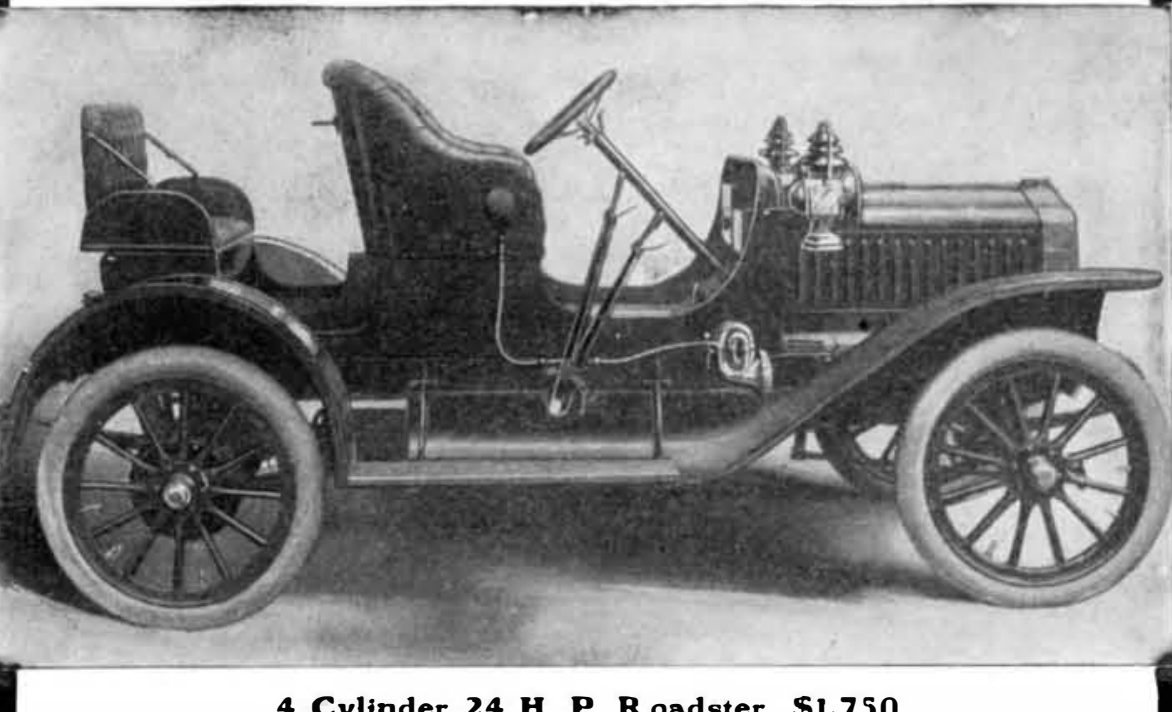

Address me personally for a complete "Maxwell" catalog, and for a personal letter of introduction to the "Maxwell" dealer nearest you, for a "Maxwell" ride over the most stubborn hill or toughest piece of road that you know.

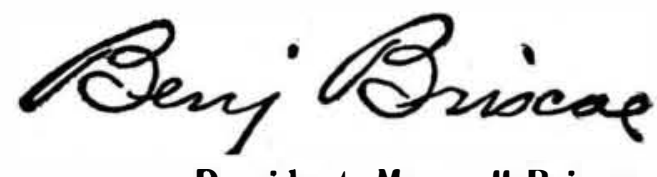

Factories : TARRYTOWN, N. Y. NEWCASTLE, MD. PAWTUCKET, R. $\mathbf{I}$.
President, Maxwell=Briscoe Motor $\mathbf{C}$. Members A. M. C. M. A. P. 0. Box III, Tarrytown, N. Y.
It is claimed that the ground contact, which consists of a brass plunger equipped with a coil spring which presses the plunger against the end of the timer shaft, will increase the speed and insure regular firing of the engine. This contact plunger is provided with a binding post and gravity nut, to which the battery ground wire is fastened instead of on the engine or frame of the machine. This is placed in the cap or cover of The timer, siving a direct ground act, and thus overcoming much of the trouble caused by different cylinders of the engine missing fire, that has heretofore been laid to coils, carbureters, plugs, batteries, and wiring. When the ground wire from the battery is fastened to the frame or engine the current must pass in to the engine through the cam-shaft bearing and out of the cam-shaft to reach the timer. The fault in this is that the cam shaft bearing is soon worn enough to re sult in a poor contact, the oil in the bearing also tending to retard the current. When the current fails to flow through the

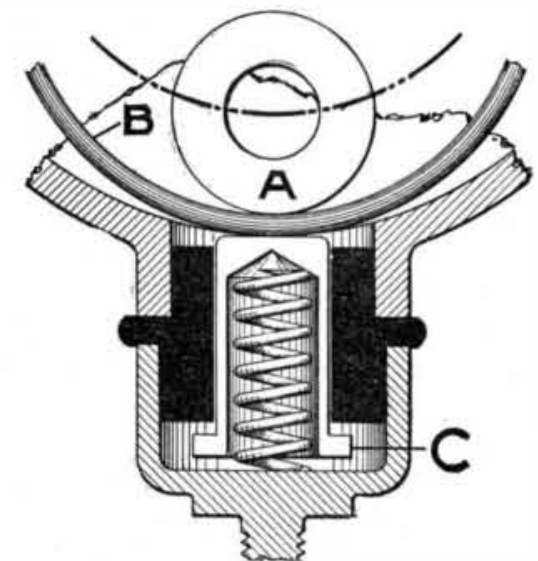

A RING AND ROLLER TIMER.

circuit, the resulting miss-fires decrease the power, and should there be a surplus of oil in the cylinder, some of the oil is thrown on the plug by the piston. When the plug fires again, the oil is burned on the plug and soon forms a carbon deposit, which stops the action of the plug. Again, a motor that is missing is apt to give off soot from the cylinder which is missing. Successive charges of gas being drawn into a cylinder and not exploded, cause the cylinder to become wet with gasoline. When this cylinder does fire, the mixture is very heavy; hence the soot and short-circuiting of the plug.

The other of the illustrations shows timer which has been improved by the addition of a loose ring between the roler and the contacts.

The difference in the diameters of the outside of the loose ring and the inside of the case in which it rolls assures a constantly changing point of contact for the action of the current. The slight

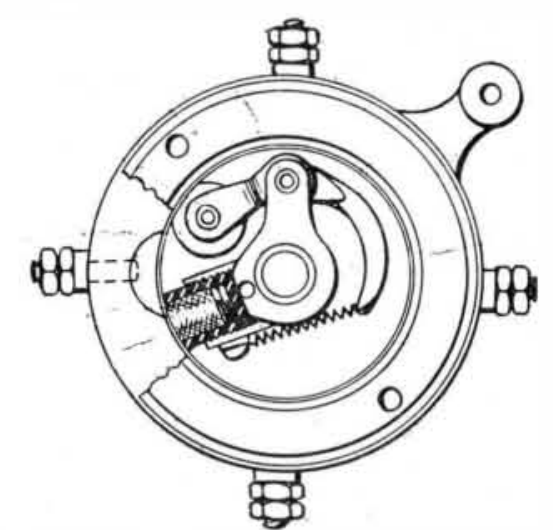

IIMER WITH CLEANING DEVICE.

abrasion consequent to this action and he slight mechanical impact of the contacting points are thus distributed over a large area. The ring, when rolled upon a contact point, acts as a direct conductor for the electric current into the case proper, bridging a gap of about one-quar. ter of an inch. As it is made of brass, the rer of an inch. As it is made of brass, the resistance is slight. It also distributes the action of the arc made when the contact is broken over the contact's entire surface. This loose ring consequently takes much of the mechanical wear from the roller inside, and the contact 